\title{
Modelling of SWOT Analysis Using Fuzzy Integrals
}

\author{
Meaza Haile $^{a} *$, Jiri Krupka ${ }^{b}$ \\ ${ }^{a}$ Institute of System Engineering and Informatics, Faculty of Economics and Administration, University of Pardubice, Studentska \\ 95, 53210 Pardubice 2, Czech Republic, Meazabi@gmail.com \\ ${ }^{b}$ Institute of System Engineering and Informatics, Faculty of Economics and Administration,University of Pardubice, Studentska \\ 95, 53210 Pardubice 2, Czech Republic, Jiri.Krupka@upce.cz
}

\begin{abstract}
To develop a strategy for an organization it is important to understand the organization and its surrounding environment. SWOT(Strength, Weakness, Opportunity and Threat) analysis is a famous tool to perform this task precisely by showing the strength, weakness of the organization and the external factors, opportunities and threats that affect its success. SWOT analysis is commonly used by businesses, however non-profit organizations also use SWOT analysis for decision-making and strategy evaluation. The limitation of SWOT analysis is it does not give weight for the factors and there is no quantified result from the analysis. The methods introduced in this paper are Sugeno lambda measure and Choquet fuzzy integral. Sugeno lambda measure is used to aggregate the importance of characteristics and Choquet fuzzy integral is used for the overall analytical evaluation of strength, weakness, opportunity and threat of a specific organization. A case study has been conducted for a currency exchange office to explain the application of the proposed approach.
\end{abstract}

\section{2016 Published by Future Academy www.FutureAcademy.org.uk}

Keywords: Choquet and Sugeno fuzzy integrals; Sugeno $\lambda$-measure; SWOT analysis

\section{Introduction}

Preparing a strategy for any organization should include a process to help identify and understand certain variables such as the purpose of the organization, its financial status, competitors, its environment and its future. Strategy evaluation is an essential process of strategy planning. Strategy evaluation process is ongoing as long the organization exists. Generally the result of a strategy evaluation include answers to questions; are the objectives of the enterprise appropriate?, are the major 
plans and policies appropriate to achieve the objectives?, do the results confirm that? And so on. It should be noted that Strategy evaluation is used or should be used not only for profit organizations but also for non-profiting organizations. Different tools and methods are used to understand the aforementioned variables; this paper particularly focuses on SWOT analysis. SWOT analysis is a preferable way to understand the position of an organization with respect to its environment (Humphrey 2005). In order to improve the success of an organization it is important to understand What the organization is doing right?, If what the organization is doing right is important?, What the organization is doing wrong?, What obstacles the organization faces?, and what opportunities the organization should exploit?. SWOT analysis is a famous tool to shade light on these questions. Using SWOT analysis the strength, weakness, opportunity and threats of an organization could be explained.

The objective of this paper is to provide methods that quantitatively evaluate SWOT analysis of an organization. Sugeno lambda measure and Choquet fuzzy integral were used to numerically analyse characteristics and sub characteristics of the SWOT analysis.

\section{Material and Methods}

As briefly mentioned in the introduction SWOT analysis is used to analyse an organization's strength, weakness, the opportunities at its disposal and the threats it is facing. These variables should be identified by experts since this is the corner stone of the whole analysis. After a selected group of experts choose SWOT sub characteristics and their priorities, the evaluation of how the organization is doing on these selected characteristics is collected based on the status of the organization. Finally, Sugeno lambda measure and Choquet fuzzy integral are used to analytically evaluate these variables.

\subsection{SWOT analysis}

SWOT analysis is used to identify the importance of sub characteristics in order to choose the best strategy for an organization. However, this practice does not provide analytical means to evaluate importance of characteristics. Some authors have proposed methods to quantify results of a SWOT analysis: Yuksel and Dagdeviren (2007) used analytic network process to develop an evaluation method for SWOT analysis. Chang and Huang (2006) discussed application of a quantification SWOT analytical method and Sevkli et al. (2012) applied fuzzy ANP, (Houben, Lenie, Vanhoof, 1999).

Businesses perform SWOT analysis when entering a new market, to evaluate their strategy or while launching a new product. SWOT stands for Strength, Weakness, Opportunity, and Threat Humphrey (2005 \& 2012). Strength and weakness are most often viewed from the organization's point of view whereas opportunities and threats are external environmental factors. Strength is what an organization has or what it can offer that others of its type do not. Weakness in opposite is what an organization does not have or does not offer others of its type do. Opportunities are advantages in the environment that an organization could use. Threats are situations in an organization's environment that could compromise the organization's success. SWOT analysis can also be used for non-profit organizations, governmental units and for individuals for decision-making situation when a desired objective has been defined (Scolozzi, Schirpke, Morri, D’amato, Santolini, 2014) and (Amin, Razmi, Zhang, 2011). SWOT sub characteristics and their priorities are highly dependent on the type of organization 
Humphrey (2005 \& 2012), (Chang, Huang, 2006) and (Yuksel, Dagdeviren, 2007) the figure (Fig. 1) below shows the general description of SWOT characteristics in a hierarchical structure.

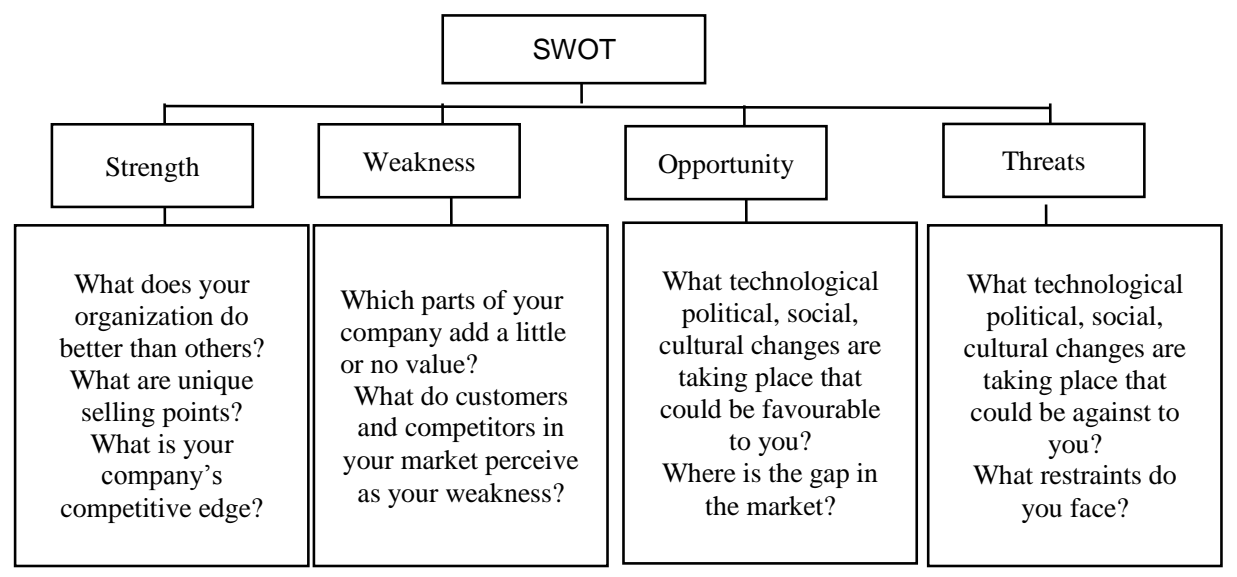

Fig. 1. SWOT analysis and some questions its sub characteristics should address (Source: Process based on Humphrey (2005 \& 2012))

What is proposed in this paper is fuzzy integral methods, if Choquet fuzzy integral method is used there no need to consider dependencies among SWOT sub characteristics and additional effect of each sub characteristic on the overall performance of a strategy is evaluated. These methods are used to quantitatively evaluate an organization's strategy and its effectiveness, based on importance of characteristics and the productivity or profit of the organization.

Expert opinion should be used to identify importance of sub characteristics. The status of the organization can be used to find actual value that shows in which parts the organization is doing well and where the strategy should focus more in the future.

\subsection{Fuzzy integrals}

Fuzzy integrals are interesting tools to summarize all the pieces of information provided by a function in a single value; this value could be a sort of average of the function, in terms of the underlying fuzzy measure. Fuzzy integrals permit the aggregation of information under different assumptions on the independence of the information sources. In particular, to model situations in which sources are independent as well as in situations in which such independence cannot be assured. Many authors have used fuzzy integrals, among are: Yang (2012), Measuring Software Product Quality with ISO Standards Based on Fuzzy Logic Technique. Authors in China have used fuzzy integrals for comprehensive framework for measuring the performance of an organization resource planning (Wei, Liou, Lee, 2008) and other researchers have used fuzzy integrals for handwritten signature verification (Singh, Madasu, Srivastava, Hamandulu, 2013) and many others (Torra, Narukawa, 2004), (Chang, Wu, Lin, 2008), and (Verkeyn, Botteldooren, Baets, 2011).

Fuzzy integrals use the term fuzzy measure which does not require additive. Fuzzy measure can be defined as:

Let $X$ be a finite index set $X=\{1, \ldots, n\}$. 
Definition 1: A fuzzy measure $\mu$ defined on $\mathrm{X}$ is a set function $\mu: \mathrm{P}(\mathrm{X}) \rightarrow[0,1]$ satisfying the following axioms (Grabisch et al. 2000) and (Sugeno 1974): $\mu(\varnothing), \mu(X)=1$, and $A \subseteq B \Rightarrow \mu(A) \leq$ $\mu(\mathrm{B})$.

The $\mathrm{P}(\mathrm{X})$ indicates the power set of $\mathrm{X}$, i.e. the set of all subsets of $\mathrm{X}$.

A fuzzy measure on $X$ needs $2^{\mathrm{n}}$ coefficients to be defined, which are the values of $\mu$ for all the different subsets of X. Fuzzy integrals are integrals of a real function with respect to a fuzzy measure, by analogy with Lebesgue integral which is defined with respect to an ordinary (i.e. additive) measure. There are several definitions of fuzzy integrals, among which the most representatives are those of Sugeno fuzzy Integral (Sugeno 1974) and Choquet fuzzy Integral (Choquet 1953).

Choquet fuzzy integral was chosen over Sugeno fuzzy integral for this paper since the Sugeno method is based on min and max, such integral calculation can only determine interval at which the measured values are possibly located, unlike Choquet fuzzy integral, which provides a unique solution.

Definition 2: Let $\mu$ be a fuzzy measure on $\mathrm{X}$. The discrete Choquet fuzzy integral of a function $\mathrm{f}$ : $\mathrm{X} \rightarrow \mathrm{IR}+$ with respect to $\mu$ is defined by

$$
C_{\mu}\left(f\left(x_{1}\right), \ldots, f\left(x_{n}\right)\right)=\sum_{i=1}^{n}\left(f\left(x_{1}\right)-f\left(x_{i-1}\right)\right) \mu\left(A_{i}\right)
$$

where $i$ indicates that the indices have been permuted so that $0 \leq f\left(x_{1}\right) \leq \ldots \leq f\left(x_{n}\right) \leq 1$. Also $A_{i}=$ $\left\{\mathrm{x}_{\mathrm{i}}, \ldots, \mathrm{x}_{\mathrm{n}}\right\}$, and $\mathrm{f}(\mathrm{x} 0)=0$.

Definition 3: Let $\lambda \in(-1, \infty)$ and let $X=\left\{x_{1}, x_{2}, \ldots, x_{n}\right\}$ be a finite set. If $(X, P(X))$ is a measurable space and if set function $\mathrm{g}_{\lambda}: \mathrm{P}(\mathrm{X}) \rightarrow[0,1]$ satisfies the following conditions, then $\mathrm{g}_{\lambda}$ is denoted by a Sugeno $\lambda$ measure and $g_{\lambda}(\varnothing)=0, g_{\lambda}(X)=1 ; A \cap B=\varnothing, A \cup B \neq X \quad g_{\lambda}(A \cap B)=g_{\lambda}(A)+g_{\lambda}(B)+\lambda g_{\lambda}(A) g_{\lambda}(B)$ that

$$
\lambda+1=\prod_{i=1}^{n}\left(1+\lambda g_{\lambda}\left(x_{i}\right)\right), \lambda>-1
$$

where $\mathrm{g}_{\lambda}\left(\mathrm{x}_{\mathrm{i}}\right)$ is fuzzy measure.

Definition 4: Let set function $\mathrm{g}: \mathrm{P}(\mathrm{X}) \rightarrow[0,1]$ be a fuzzy measure on measurable space $(\mathrm{X}, \mathrm{P}(\mathrm{X}))$, and $h: X \rightarrow[0,1]$ be a measurable function on $X$. If $h\left(x_{1}\right) \leq h\left(x_{2}\right) \leq \ldots \leq h\left(x_{n}\right), A_{i}=\left\{x_{i}, x_{i+1}, \ldots, x_{n}\right\}$ then (Grabisch, Murofushi, Sugeno, 2000), (Choquet 1953)

$$
E^{d e f}=\int h d g^{d e f}=h\left(x_{1}\right) g\left(A_{1}\right)+\sum_{i=2}^{n}\left(h\left(x_{i}\right)-h\left(x_{i-1}\right)\right) g\left(A_{i}\right)
$$

Where Edef denotes the overall function $\mathrm{h}(\mathrm{xi})$ is viewed as the performance of sub characteristic xi of the organization at a specific time. $g\left(A_{i}\right)$, express the grade of importance for the subset $A_{i}$. The fuzzy integral of $\mathrm{h}\left(\mathrm{x}_{\mathrm{i}}\right)$ with respect to $\mathrm{g}$ denotes the overall evaluation.

By using equation (3) the overall evaluation for each, Strength, Weakness, Opportunity and Threat is obtained. From these aggregated values, status of an organization with respect to its environment is determined. The organization can use the output for amending a strategy and/or for developing a new strategy based on the numbers obtained from the fuzzy aggregation. The method can also be used to compare different strategies.

\subsection{Application procedure of fuzzy integrals}

The following are the main steps in evaluating strategy and its effectiveness: 
1. Change the importance values to decimal values between 0 and 1

2. Change the performance values to decimal values between 0 and 1

3. Calculate for $\lambda$ for each level

$$
\lambda+1=\left(1+\lambda g_{\lambda}(S 1)\right)\left(1+\lambda g_{\lambda}(S 2)\right)\left(1+\lambda g_{\lambda}(S 3)\right), \lambda>-1
$$

4. Calculate the combined effect of sub characteristics using the formula

$$
g_{\lambda}(A, B)=g_{\lambda}(A)+g_{\lambda}(B)+\lambda g_{\lambda}(A) g_{\lambda}(B)
$$

and so on until all sub characteristics at this level are analysed

5. Calculate evaluation value for higher level according to equation (3).

The result from this analysis is aggregated performance of the strength of the organization; the same procedures are used to determine Weakness, Opportunity and Threats. Based on the result we can evaluate existing strategy and decide whether to keep the strategy or propose a new one.

\section{Discussion and Result}

This paper describes how to use Sugeno lambda measure and Choquet fuzzy integral to analytically analyse characteristics and sub characteristics of the SWOT analysis. The importance of higher characteristics is evaluated based on sub characteristics. The hierarchical structure of SWOT analysis represents sub characteristics of the SWOT analysis for each characteristics and the success of a strategy is valuated based on the importance and weight of these sub characteristics. Evaluation of a strategy of an organization is highly subjective and uncertain; hence, it is appropriate to use fuzzy measure instead of traditional additive measures.

Fuzzy integrals consider the worth of each sub characteristic and their performance as an input. It is considered that a perfect organization is strong, has overcome all its weaknesses, exploited all the possible opportunities and has no threats. Although that is impossible, an organization's strategy is expected to have a higher value for strength and opportunity and a lower value for weakness and threat.

The Sugeno $\lambda$-measure applied in this paper is one of fuzzy measures used widely, and has plenty applications recently, including pattern recognition. SWOT sub characteristics for a specific organization could be selected and prioritized based on expert opinions or experience of the organization. After obtaining the individual importance and performance of the sub characteristics, fuzzy integrals are applied to find the overall performance of the characteristics (Strength, Weakness, Opportunity and Threats).

The main procedures applied in the proposed method for evaluating SWOT characteristics and their effectiveness for a currency exchange office is discussed in the following sub section.

\subsection{Application of proposed method for foreign currency exchange office}

There are many currency exchange offices in Prague some of these offices buy and sell foreign currencies for a small difference and they make their profit by buying and selling a large amount of foreign currencies per day while others make a better profit from each unit of currency they buy and sell and make significantly less amount of transaction. The currency exchange company, studied here, 
uses the second method and has more than five offices each making a small amount of transaction a day.

The data shown in the following table (Table 1) was gathered from one of these currency exchange offices. This data was used only as an empirical example to clarify the application of the discussed methods. The SWOT sub characteristics were selected and assigned importance and performance value by the staff of the company based on their experience in that office and in comparison of their other exchange offices located in Prague. The following table contains the data after it was transformed in to $[0,1]$ scale.

Table 1. Input data from experts and calculated lambda values

\begin{tabular}{|c|c|c|c|c|c|}
\hline & \multicolumn{2}{|c|}{ Characteristics } & \multirow{2}{*}{$\begin{array}{c}\text { Importance } \\
0.6\end{array}$} & \multirow{2}{*}{$\begin{array}{c}\text { Weight } \\
0.9\end{array}$} & \multirow[t]{2}{*}{$\lambda$} \\
\hline & Location & $\mathrm{S} 1$ & & & \\
\hline \multirow[t]{3}{*}{ Strength } & Customer service & $\mathrm{S} 2$ & 0.4 & 0.9 & -0.693 \\
\hline & Promotion & $\mathrm{S} 3$ & 0.4 & 1 & \\
\hline & Too many people & W4 & 0.2 & 0.2 & \\
\hline \multirow[t]{3}{*}{ Weakness } & Reserved money & W2 & 0.5 & 0.7 & -0.46 \\
\hline & Not a tourist center & W3 & 0.5 & 0.8 & \\
\hline & Restaurant & $\mathrm{O} 1$ & 0.6 & 0.4 & \\
\hline \multirow[t]{3}{*}{ Opportunity } & No direct VAT & $\mathrm{O} 2$ & 0.2 & 0.7 & -0.97 \\
\hline & Hotels and hostels & $\mathrm{O} 3$ & 0.7 & 0.9 & \\
\hline & Changing to euro & $\mathrm{T} 1$ & 0.8 & 0.3 & \\
\hline \multirow[t]{2}{*}{ Threat } & ATM & $\mathrm{T} 2$ & 0.5 & 0.4 & -0.92 \\
\hline & Two more places & $\mathrm{T} 3$ & 0.5 & 0.5 & \\
\hline
\end{tabular}

As shown in the above table (Table 1), strength of this company is the location, customer service and promotion. The importance of a location of an exchange office is evaluated to be 0.6 out of 1 and the location of this particular exchange is very good since it is located on the building right next to a traffic light, 0.9 out of 1 . They also have a good customer service, which they believe is 0.9 out of 1 and the importance of good customer service for the success of the exchange is evaluated to be 0.4. The importance of promotion is also 0.4 for exchange and they have a Very good promotion.

It is important to note that this experiment was only done for one branch of the exchange company to explain the application of the method.

The step by step procedure to evaluate the SWOT analysis performed for the exchange office is shown below

1. $\lambda$ was calculated for each level

$$
\begin{aligned}
& \lambda+1=\left(1+\lambda g_{\lambda}(S 1)\right)\left(1+\lambda g_{\lambda}(S 2)\right)\left(1+\lambda g_{\lambda}(S 3)\right), \lambda>-1 \\
& \lambda+1=(1+0.6 \lambda))(1+0.4 \lambda)(1+0.4 \lambda), \lambda>-1 \text { for Strength (S) }
\end{aligned}
$$

2. The data was arranged according to $h\left(x_{1}\right) \leq h\left(x_{2}\right) \leq \ldots \leq h\left(x_{n}\right)$

3. Combined effect of sub characteristics was calculated using fuzzy measure

$$
\begin{gathered}
g_{\lambda}(S 1, S 3)=0.83, g_{\lambda}(S 2, S 3)=0.69 \\
g_{\lambda}(S)=g_{\lambda}(S 2)+g_{\lambda}(S 1, S 3)+(-0.693) g_{\lambda}(S 2) g_{\lambda}(S 1, S 3)=1
\end{gathered}
$$

The same procedure is used for $\mathrm{W}, \mathrm{O}$ and $\mathrm{T}$ 
4. The aggregated value for each characteristics was calculated using equation (3)

$$
\begin{gathered}
E^{d e f}=h\left(x_{1}\right) g_{\lambda}(S 1, S 2, S 3)+\left(h\left(x_{2}\right)-h\left(x_{1}\right)\right) g_{\lambda}(S 2, S 3)+\left(h\left(x_{3}\right)-h\left(x_{2}\right)\right) g_{\lambda}(S 3) \\
=0.9 \times(1)+(0.9-0.9) \times 0.83+(1-0.9) \times 0.4=0.94
\end{gathered}
$$

The same procedure is used to find the values for the rest of the characters. The result of the evaluation is shown in the following table:

Table 1. Evaluated value for strength $\mathrm{S}$, weakness $\mathrm{W}$, opportunity $\mathrm{O}$ and threat $\mathrm{T}$

\begin{tabular}{cccc}
\hline Strength & Weakness & Opportunity & Threat \\
\hline 0.94 & 0.25 & 0.54 & 0.44 \\
\hline
\end{tabular}

Based on these results the company over all has good strength but they also have weakness they could improve their weakness more by reserving more money and they could change their offices to a more tourist center since the combined effect of these two sub characteristics is significant. The opportunity at their disposal is $\mathbf{0 . 5 4}$, these are the factors the company could not control, but in the future they could choose a place in an area where there are more hostels and restaurants in order to increase their success. Finally the threat is that they worry about the the country changing the currency to Euro and that makes them cautious to invest more in the business and that many people are using credit cards, unfortunatley they can not do anything about that.

\section{Conclusion}

Strategy evaluation is the most crucial part of strategy life cycle; SWOT analysis is one of the tools used in strategy evaluation to understand an organization with respect to its internal and external environment. However, SWOT analysis does not provide a way to analytically analyse and evaluate a strategy. Although some multiple criteria decision methods have been used to analytically analyse the importance of SWOT sub characteristics for comparing different strategies, what is discussed in this paper is fuzzy integral methods where considering dependencies is not an issue and the method can also be applied to evaluate an organization's strategy. The result from this method could be used as a report for stakeholders on how an organization is performing. By using fuzzy integral methods, organizations will be able to evaluate their current strategy and its effectiveness with respect to the status of the organization. That is to see how effective the strategy they are applying is, and what they should change in the future. The expected result, from the above method is a numerical value on how the current strategy is doing in driving the organization towards its goal, and which part of the strategy should the organization improve.

These methods can also be applied to compare strategies for bigger organizations, profit or nonprofit. In that case, it is recommended to use linguistic variables and fuzzy defuzification methods to record the performance of selected variables, since it is difficult to exactly quantify performance of sub characteristics for big organizations.

Although applying fuzzy integral methods will provide a way to quantitatively evaluate a strategy, SWOT analysis is an expensive and time-consuming task and cannot be done as often as we would like 
to, and does not guarantee success since some effects of a strategy may not be visible at a certain time.

Using expert systems like reasoning to continuously monitor and record effects of a strategy is recommended for further work.

\section{Acknowledgements}

This article was supported by the projects No. SGS_2016_023 of the Ministry of Education, Youth and Sports of CR with title "Economic and social development in private and public sector" at the Faculty of Economics and Administration, University of Pardubice.

\section{References}

Amin, S.H., Razmi, J., \& Zhang, G. (2011). Supplier selection and order allocation based on SWOT analysis and fuzzy linear programming, Expert Systems with Appl., 38, 334-342.

Chang, Ch.W., Wu, Ch.R., \& Lin H.L. (2008). Integrating Fuzzy Theory and Hierarchy Concepts to Evaluate Software Quality, Springer Science and Business Media LLC, 263-276.

Chang, H.H., \& Huang, W.Ch. (2006). Application of a quantification SWOT analytical method. Mathematics and Computer Modelling, 43, 158-169.

Choquet G., (1953). Theory of capacities, Annales de l'Institut Fourier, 5, 131- 295.

Grabisch, M., Murofushi,, T., \& Sugeno, M. (2000). Fuzzy Measures and Integrals. Theory and Applications (edited volume). Studies in Fuzziness. Physica Verlag.

Houben, G., Lenie, K., \& Vanhoof, K. (1999). A knowledge-based SWOT-analysis system as an instrument for strategic planning in small and medium sized enterprises. Decision Support System, 26, 125-135.

Humphrey, A. (2005). SWOT Analysis for Management Consulting, SRI Alumni Newsletter. Retrieved from SRI International.

Humphrey, A. Research: The Science of Team Action Management [online] [2012-06-03], The Father of TAM, TAM UK Retrieved. Available on: http://www.tamplc.com/research.htm

Scolozzi, R., Schirpke, U., Morri, E., D’Amato, D., \& Santolini, R. (2014). Ecosystem services-based SWOT analysis of protected area for conservation strategies, J. of Environmental Management., 146, $543-551$.

Sevkli, M., Oztekin, A., Uysal, O., Torlak, G., Turkyilmaz, A., \& Delen, D. (2012). Development of a fuzzy ANP based SWOT analysis for the airline industry in Turkey. Expert Systems with Appl., 39, 14-24.

Singh, M., Madasu, V.K., Srivastava, S., \& Hamandlu, M. (2013). Choquet integral based verification of handwritten signatures, Journal of intelligent and fuzzy system, 24 (1), 145-161.

Sugeno, M. (1974). Theory of Fuzzy Integrals and its Applications, Tokyo Institute of Technology, Japan.

Torra, V., \& Narukawa, Y. (2004). On the interpretation of some fuzzy integrals, Modelling decisions for artificial intelligence, Springer Berlin Heidelberg, 3131, 316-326.

Verkeyn, A., Botteldooren, D., \& De Baets, B. (2011). Generic learning of fuzzy integrals accumulating human-reported environmental stress, Applied Soft Computing, 11, 305-314.

Wei, Ch.Ch., Liou, T.S., \& Lee, K.L. (2008). An ERP performance measurement framework using a fuzzy integral approach, Journal of manufacturing technology management, 19, 607-626.

Yang, H. (2012). Measuring Software Product Quality with ISO Standards Based on Fuzzy Logic Technique, Springer- Verlag Berlin Heidelberg, AISC 137, 59-67.

Yuksel, I., \& Dagdeviren, M. (2007). Using the analytic network process (ANP) in a SWOT analysis - A case study for a textile firm. Information Sciences, 177, 3364-3382. 